\title{
Thrombotic Occlusion of the Large Pulmonary Arteries
}

\author{
STUART R. REUBEN* \\ From the Cardiac Investigation Unit, Leeds General Infirmary
}

The syndrome of massive thrombosis of the main pulmonary arteries and its clinical and pathological features have been well documented over the past 25 years, but the diagnosis of this relatively uncommon condition (about 200 reported cases), even though suspected, is seldom made during life. In a number of cases the diagnosis can hardly be made because the thrombosis is a terminal event, or is an insidious occurrence in patients already suffering from chronic cardiac or pulmonary disease. In such conditions the thrombosis merely increases the severity, and determines the final result by increasing the work load on the right ventricle. On the other hand, it may be the cause of an acute and rapidly fatal illness in a patient previously enjoying good health. It is because we feel that this syndrome is commoner than is generally supposed, and because of some of its bizarre manifestations, and its ability to simulate other organic and even mental disease states, that we are reviewing previously reported cases, and presenting two new ones with unusual features.

\section{Case Reports}

Case 1. A 33-year-old man was admitted as an emergency to the Intensive Care Unit in March 1965, following a barbiturate overdose. At examination he was comatose, with well-maintained spontaneous respiration, but tolerating a cuffed endotracheal tube. $\mathrm{He}$ was centrally cyanotic with a sinus tachycardia of 140 / min. and a blood pressure of 95/50 mm. Hg. General examination of the heart and lungs revealed no abnormality.

Relevant investigations then were as follows. Blood barbiturate level, $2 \mathrm{mg} .100 \mathrm{ml}$. Arterial blood gas analysis: $p \mathrm{H}, 7.265 ; \mathrm{PCO}_{2}, 36.5 \mathrm{~mm}$. $\mathrm{Hg} ; \mathrm{Po}_{2}, 46.1$ $\mathrm{mm}$. $\mathrm{Hg}$ (before $\mathrm{O}_{2}$ therapy); standard $\mathrm{HCO}_{3}, 16.5$ $\mathrm{mEq} / 1$.; base deficit, $9.5 \mathrm{mEq} / 1$. PCV, 44 per cent.

\footnotetext{
Received December 13, 1966.

* Present address: Department of Medicine, Brompton Hospital, London S.W.3. I I
}

Blood chemistry and urea, normal. Chest $x$-ray film showed pulmonary congestion.

He responded to conventional resuscitative therapy, including oxygenation, correction of his acidosis, and intravenous fluid replacement, and within three days of admission he was transferred to the care of a psychiatrist for investigation and treatment. A chest $x$-ray film on admission to the psychiatric ward (Fig. 1) showed minimal congestive lung changes, with a prominent right border of the heart, but physical examination was entirely negative apart from the finding of a mild sinus tachycardia. It was learnt that the patient had had a dysphonia (probably hysterical in ætiology) since the age of 17, and that the previous year he had received psychiatric treatment for auditory hallucinations, and had been diagnosed as a schizophrenic.

During the second week of his stay in hospital treatment for depression was started, but he became increasingly restless and confused, with a return of auditory hallucinations. Five days later he became acutely ill with dyspnœe and a hacking non-productive cough. He was slightly cyanotic, with cold moist extremities, a regular tachycardia, and raised jugular venous pressure. There was evidence of right ventricular enlargement, but no murmurs or gallop rhythm were detected. An electrocardiogram revealed a sinus tachycardia with right atrial hypertrophy, and a chest $x$-ray film showed an enlarged right ventricle (Fig. 2). A diagnosis of congestive heart failure of uncertain ætiology was made, and treatment with digitalis, mercurial diuretics, and bed-rest was instituted.

Four days later the patient complained of severe epigastric pain and was found to be still dyspnœic with a rapid, irregular, feeble pulse, raised jugular venous pressure, with conspicuous " $a$ " waves, right ventricular hypertrophy, and hepatomegaly. A loud pleural friction rub was heard over the left lower lobe, but there was no evidence of thrombophlebitis or peripheral venous thrombosis. A diagnosis of pulmonary embolism and infarction was considered, and an electrocardiogram at this time showed paroxysmal atrial tachycardia with block (Fig. 3), suggesting the possibility of digitalis intoxication. Serum electrolytes were within normal limits 621 


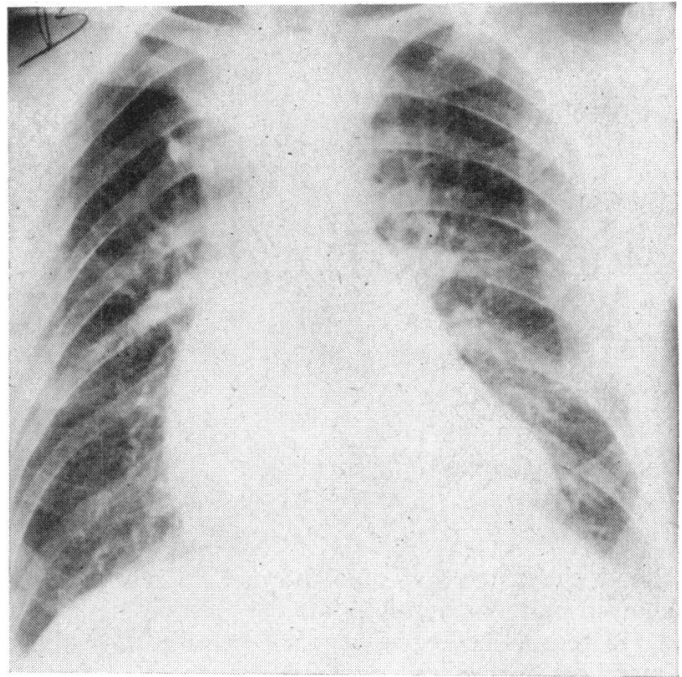

Fig. 1. Case 1. Antero-posterior chest $x$-ray film on admission to the psychiatric ward, showing congested lung fields, a prominent right border of the heart, and an enlarged left atrium.

The following day he became desperately ill with increasing dyspnœa, cyanosis, epigastric and left pleuritic pain, and a retrosternal oppressive feeling. Examination now revealed an apical gallop rhythm in addition. The electrocardiogram at this stage showed slow atrial flutter, with a variable ventricular response of 200 a minute and digitalis effect. Intravenous propranolol was given (8 mg., at $1 \mathrm{mg}$. $/ \mathrm{min}$.) and the rhythm reverted to sinus tachycardia.

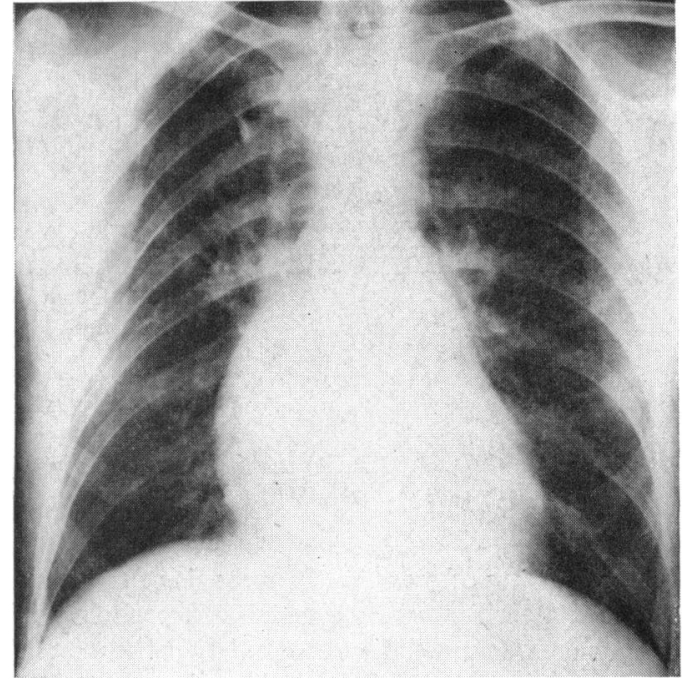

Fig. 2. Case 1. Antero-posterior chest $x$-ray film, a month later, taken at the onset of right heart failure, and showing a more prominent right border of the heart and pulmonary congestion.

After this episode, heart failure was progressive and digitalis therapy was cautiously started again, but despite this régime the downward course continued unabated, with the patient becoming increasingly dyspnœic, cyanotic, restless, and confused, and bizarre hallucinations developed. He remained hypotensive and soon became oliguric, with a blood urea rising to $180 \mathrm{mg} . / 100 \mathrm{ml}$. Clinically he was icteric and a serum bilirubin was $2 \cdot 1$ mg./100 ml. Polycythæmia developed, the patient

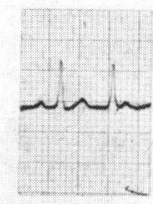

1.

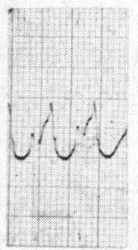

VI

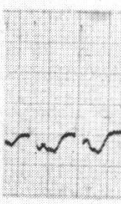

11.

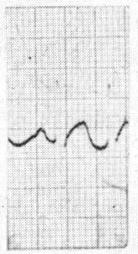

$\sqrt{2}$

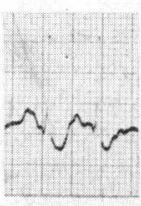

III

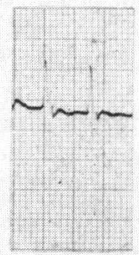

V3

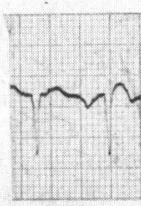

aVR

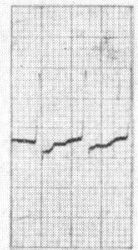

V4

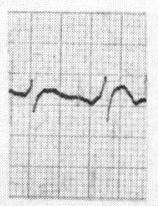

OVL

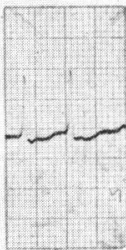

V5

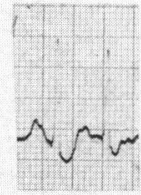

aVF

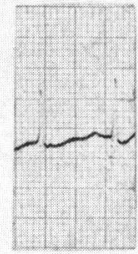

V6

FIG. 3. Case 1. Standard 12-lead electrocardiogram showing paroxysmal atrial tachycardia with a variable block, and digitalis effect. 
having a hæmoglobin of $20 \cdot 2 \mathrm{~g} . / 100 \mathrm{ml}$. and a PCV of 64 per cent, and a final chest $x$-ray film showed both right atrial and slight ventricular enlargement, with avascularity of the left lung field (Fig. 4). Terminally he suffered several synocopal attacks, stopped breathing, and died.

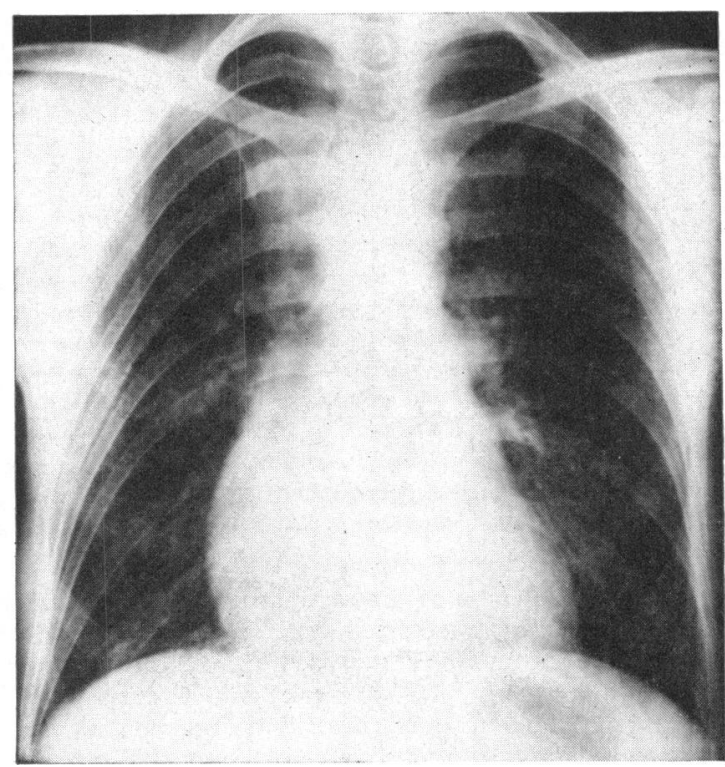

FIG. 4. Case 1. Antero-posterior chest $x$-ray film showing an oligæmic left lung field, an irregular left main pulmonary artery, and right atrial enlargement.

Necropsy. The heart weighed $360 \mathrm{~g}$. and the myocardium and valves were normal. There was right atrial and right ventricular dilatation but no hypertrophy of the walls.

The left main pulmonary artery was almost occluded by a large thrombus extending down into the left lower lobe. There was organization in the deeper parts of the thrombus, with superficial lamination, but one could not determine whether this was thrombosis in situ, or embolic thrombus with superadded local thromboses. The age of the thrombus was at least four weeks. There was a large hæmorrhagic infarct of the left lower lobe, with superimposed fibrinous pleurisy.

The liver showed a "nutmeg" appearance, and extensive examination of the iliac, femoral, and calf veins failed to reveal thrombus.

Comment. The patient presented with unexplained right heart failure, and though the diagnosis of pulmonary infarction with massive thrombo-embolism was suspected, he was at no time fit enough to undergo investigations to confirm the diagnosis.

His symptom complex was somewhat bizarre, with the usual features of dyspnœa, cough, cyanosis, and right heart failure (Savacool and Charr, 1941; Middleton,
1943; Ball, Goodwin, and Harrison, 1956; Brenner, 1935), but mental symptoms almost verging on frank psychosis were present (Hollister and Cull, 1956), and abdominal pain was his main complaint (Middleton, 1943).

Unusual features were varying cardiac arrhythmias, a poor response to conventional therapy for congestive heart failure with the development of digitalis toxicity, a low cardiac output, and polycythæmia, jaundice, and ultimately uræmia. No cardiac murmurs, or abnormal splitting or accentuation of the pulmonary component of the second heart sound were present.

Although the peripheral veins were free of thrombus at necropsy, it was not possible to decide whether the thrombus arose in situ or was embolic with superadded local deposition of clot. The cause of the pulmonary artery thrombosis remains uncertain, and the role of hypoxæmia as the result of the barbiturate overdose cannot be determined.

Case 2. A 48-year-old man was first admitted to hospital in May 1965, with a 12-month history of progressive exertional dyspncea and marked ankle swelling of seven days' duration. At this time, clinical examination merely revealed peripheral œdema, with no rise in jugular venous pressure, cardiomegaly, or præcordial murmurs. The electrocardiogram (Fig. 5) showed sinus rhythm, left atrial hypertrophy, and a normal electrical axis. The chest $x$-ray film (Fig. 6) showed left atrial hypertrophy, and dilatation of the atrial appendage, with pulmonary congestion, suggesting mitral stenosis.

Treatment with digitalis and diuretics was instituted, and there was considerable improvement, though later electrocardiograms showed evidence of right ventricular hypertrophy and a shift of the electrical axis to the right, with clockwise rotation of the heart (Fig. 5). He remained well for the rest of the year, but was readmitted in January 1966 because of a return of exertional dyspnoea, ankle swelling, and a recent small hæmoptysis. Examination showed a sinus tachycardia and raised jugular venous pressure with prominent " $v$ " waves. Clinically, there was evidence of right ventricular hypertrophy and there was a soft apical systolic murmur, but the pulmonary component of the second sound was not accentuated. The electrocardiogram once more showed sinus rhythm, left atrial hypertrophy, right ventricular hypertrophy, and right axis deviation, with clockwise rotation of the heart.

Soon after admission he suddenly developed left loin pain with radiation to the left groin, and was thought to have had a renal embolus. At this time, the patient had several episodes of unexplained confusion, disorientation, and belligerent behaviour, but there was no alteration of his blood pressure which remained at 150/90 mm. Hg. Transseptal cardiac catheterization was performed, and later atrial fibrillation supervened. The catheterization results were: $\mathrm{RV}$ pressure, $90 / 0 \mathrm{~mm} . \mathrm{Hg}$; LA pressure, 50/15 mm. Hg; LV pressure, $140 / 0 \mathrm{~mm}$. $\mathrm{Hg}$. The cardiac output (Coomassie Blue dye dilution technique) was $1.71 . / \mathrm{min}$., and there was a gradient of 20 $\mathrm{mm}$. $\mathrm{Hg}$ across the mitral valve. A diagnosis of tight mitral stenosis with severe pulmonary hypertension was 
$28 \cdot 4 \cdot 65$

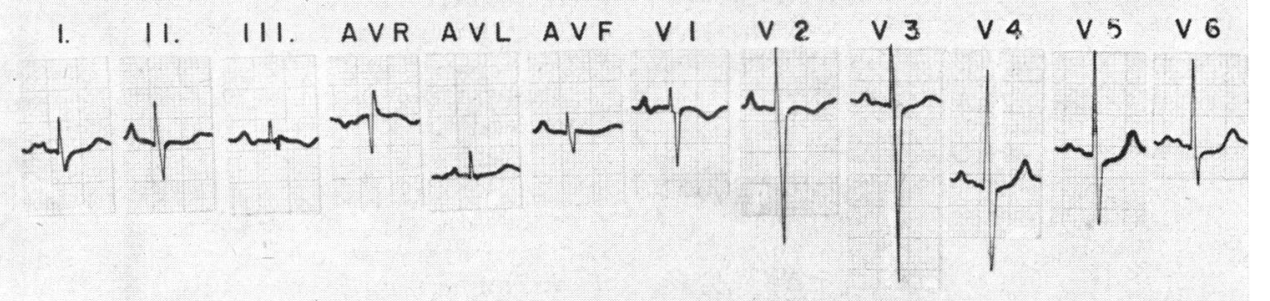

$26 \cdot 1 \cdot 66$

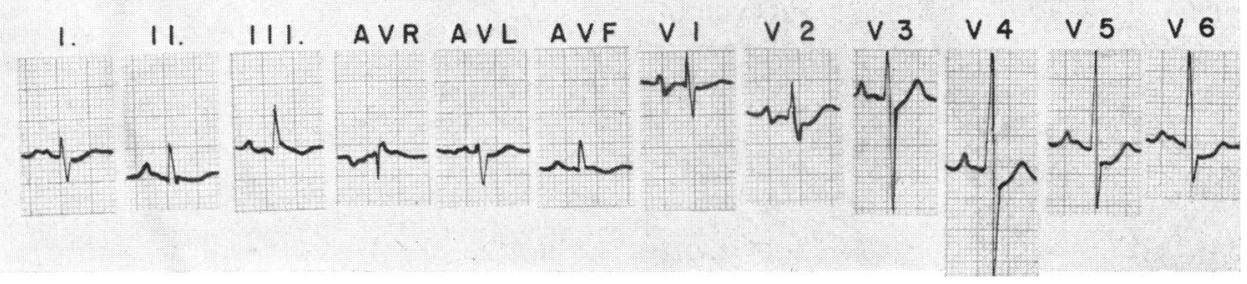

FIG. 5. Case 2. Standard 12-lead electrocardiogram showing marked left atrial hypertrophy (28/4/65) and left atrial enlargement, right ventricular hypertrophy, and right axis deviation (26/1/66).

made. After catheterization, intravenous pyelography showed a non-functioning left kidney, confirming the diagnosis of a left renal embolus.

The patient remained unconscious following catheterization, barely responding to painful stimuli, and it was 18 hours before he fully regained consciousness and a lucid mental state. At no time during this period were there any abnormal neurological signs. In view of the

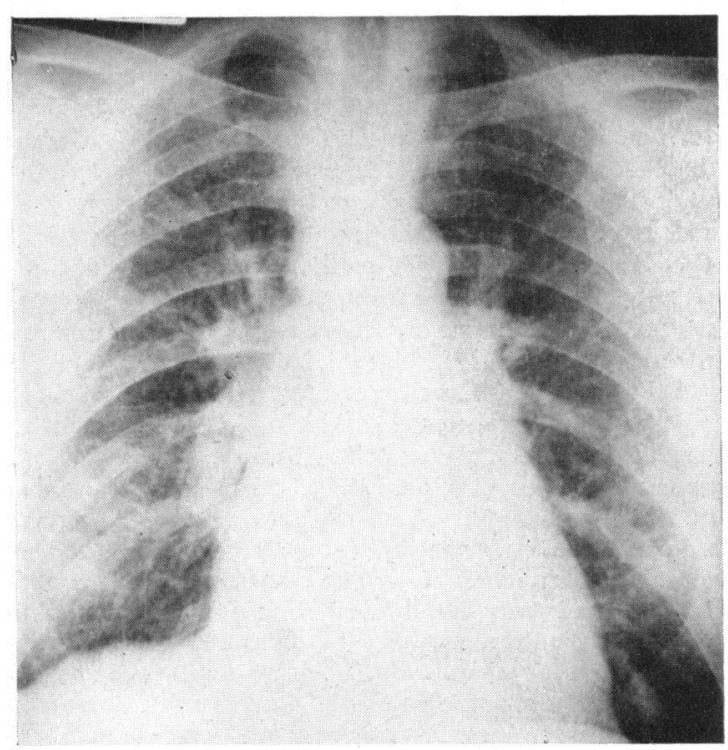

FIG. 6. Postero-anterior chest $x$-ray film showing left ventricular and atrial enlargement and pulmonary congestion. probable renal embolus and rapid atrial fibrillation, anticoagulant therapy was started, but the patient's condition deteriorated. Dyspnœa increased, the venous pressure rose, and peripheral œdema and hepatomegaly appeared. Following hæmaturia the patient became oliguric. The blood urea rose to $168 \mathrm{mg} . / 100 \mathrm{ml}$., and jaundice appeared (serum bilirubin $2.3 \mathrm{mg}$. $/ 100 \mathrm{ml}$.). Syncopal attacks were succeeded by death.

Necropsy. The heart weighed $650 \mathrm{~g}$. and both atria were dilated. There was gross hypertrophy of the left atrium and ventricle and slight dilatation of the right ventricle.

The mitral valve showed severe irregular oval stenosis with calcific nodules along the edges of the orifice and fusion and thickening of the chordæ. There was slight dilatation of the tricuspid ring and some fibrosis of the aortic valve.

The right main pulmonary artery contained a large thrombotic mass occluding more than 50 per cent of the lumen diameter. The thrombus was firm and adherent, with organization in its deeper parts and superficial lamination, and histologically was several weeks old. The lungs were congested and odematous.

The left kidney showed almost total hæmorrhagic infarction; the right kidney was swollen and the medulla was soft on palpation. Both renal arteries had extensive diffuse atheroma, and there was a polypoidal atheromatous plaque, $1 \mathrm{~cm}$. from the orifice of the left renal artery, to which antemortem thrombus was adherent, thus producing almost total obliteration of the lumen. The liver weighed $1650 \mathrm{~g}$. and showed conspicuous chronic venous congestion.

Comment. The patient presented with unexplained right heart failure, and though the diagnosis of mitral 
stenosis was suggested by the chest $x$-ray film, fluoroscopy, and the electrocardiogram, it was only confirmed nine months later by cardiac catheterization. A noteworthy feature in this case was that a mitral diastolic murmur was never heard, and the pulmonary component of the second heart sound was not accentuated, despite the presence of severe pulmonary hypertension. Serial electrocardiograms showed the development of left atrial hypertrophy, right ventricular hypertrophy, and a swing of the electrical axis of the heart from left to right.

The patient remained in sinus rhythm (presumably) until the final week of the illness, when paroxysms of atrial fibrillation occurred. Most probably it was the advent of atrial fibrillation which determined the embolic manifestations of the illness, but whether this was due to the mitral stenosis or to the development of thrombotic pulmonary artery disease remains unknown.

Case 2 contrasts well with Case 1 in that a major pulmonary artery thrombosis developed in a patient with rheumatic heart disease with severe pulmonary hypertension.

It seems not unreasonable to suggest that in such cases of pulmonary hypertension, factors for the in situ development of pulmonary artery thrombosis are the chronic hypoxæmia many of them endure, combined with the low cardiac output and sluggish pulmonary circulation due to the chronically raised pulmonary venous pressure. Moreover, as Brenner (1935) has shown, patients with pulmonary hypertension frequently develop arteriosclerosis in the branch and major pulmonary arteries.

\section{Discussion}

The true incidence of this condition is not fully known, but Middleton (1943), reviewing the necropsies performed over a 16-year period at the Wisconsin General Hospital, found 53 cases of thrombosis of major pulmonary arteries. Magidson and Jacobson (1955) recorded an incidence of 0.2 per cent ( 7 cases in 35,003 necropsies) on reviewing the necropsy records of the Los Angeles County Hospital over a 20-year period; the incidence of pulmonary embolism over this time was 4.2 per cent (1469 cases). Ball et al. (1956) presented 23 cases of massive thrombotic occlusion of large pulmonary arteries, 9 of which were seen during life. In 19 cases there was associated chronic cardiac or parenchymal lung disease, but in 4 there was no associated disease present, and in 7 of them it was considered at necropsy that the thrombosis had arisen in situ.

The symptoms of thrombotic occlusion of the main pulmonary arteries develop insidiously, and are those of right heart failure and low cardiac output, with dyspnœa and hæmoptysis being the commonest presenting symptoms (Middleton, 1943; Kampmeier, 1934; Covey, 1943; Fowler, 1934).

Confusion and restlessness often occur in this syndrome and in other cardiopulmonary disorders where there is diminished cerebral blood flow and hypoxæmia, but our first case presented with a frank psychotic picture with bizarre hallucinations and delusions. Hollister and Cull (1956) record a similar case, and it can be postulated that the low cerebral blood flow and hypoxæmia uncover a psychotic state in a person with an abnormal personality or an inborn tendency to such a psychiatric syndrome.

Tench (1955) described a triad of tachycardia, digitalis toxicity, and resistant œdema in a group of patients on routine treatment of congestive heart failure who had recurrent pulmonary emboli, and Wolff (1952) discussed cardiac arrhythmias in massive pulmonary thrombo-embolism. Our first case developed digitalis toxicity and cardiac arrhythmias, and like Tench, we feel that the occurrence of such sensitivity to digoxin, resistant heart failure, and variable cardiac rhythms during the routine treatment of congestive heart failure, should suggest pulmonary thrombo-embolism. Abdominal pain and jaundice were features in our cases and have been fully discussed by Middleton (1943).

The physical signs of thrombotic occlusion of the pulmonary arteries are fully discussed by Ball $e t$ al. (1956) and Magidson and Jacobson (1955), and are those of right heart failure, with cyanosis as an added feature.

The electrocardiogram is invaluable in this syndrome because as well as showing cardiac arrhythmias, it may reveal right ventricular hypertrophy or right atrial enlargement. The demonstration of an electrical axis changing from left to right in serial recordings is particularly helpful in the diagnosis of pulmonary thrombosis (Hollister and Cull, 1956).

The radiological criteria for diagnosis have been discussed by Hanelin and Eyler (1951) and the fluoroscopic findings by Keating (1955).

Pathology. In the majority of cases of thrombotic occlusion of the major pulmonary arteries, it has been considered that the thrombosis is secondary to embolism. However, many authors (Ball et al., 1956; Brenner, 1935; Magidson and Jacobson, 1955) describe cases in which the thrombosis has arisen in situ, and this is the contention in our first case. Ball et al. (1956) have discussed the criteria for the differentiation of thrombosis in situ from thrombosis secondarily to embolism.

Pulmonary infarction may be found at necropsy. There appears to be no correlation between the presence or absence of infarction with thrombosis in situ, or with associated chronic cardio-pulmonary disease (Brenner, 1935; Keating et al., 1953). Massive thrombotic occlusion of the pulmonary arteries is most commonly associated with chronic parenchymal lung disease or rheumatic heart disease with 
associated pulmonary hypertension. However the syndrome has been reported without chronic cardiopulmonary disease (Ball et al., 1956; Covey, 1943; Dimond and Jones, 1954).

Pulmonary tuberculosis and anthracosilicosis are the commonest chronic lung diseases associated with thrombotic occlusion of large pulmonary arteries, and were present in 43 per cent of the cases described by Savacool and Charr (1941), but pulmonary fibrosis, emphysema, and chronic purulent bronchitis are also common. Mitral stenosis is the most frequent cardiac condition associated with the syndrome (Fowler, 1934).

Congenital heart disease, syphilitic pulmonary arteritis, dehydration, and hypoxæmia have infrequently been reported in association with pulmonary artery thrombosis (Brenner, 1935). It is presumed that these conditions act by causing pulmonary hypertension and possibly pulmonary arteriosclerosis, thus reducing the cardiac output and causing stasis of blood in the pulmonary arteries.

\section{SUMMARY}

Two cases of thrombosis of the main pulmonary arteries are reported. In both patients the thrombosis was thought to have arisen in situ. In one case, mitral stenosis and severe pulmonary hypertension were present, while in the other there was no associated chronic cardio-pulmonary disease.

Previously reported cases have been reviewed and the clinical features, pathology, and ætiology of the syndrome have been discussed.

I wish to thank Dr. D. Taverner for permission to publish Case 1, and Dr. D. R. Smith for Case 2, and would like to express my gratitude to $\mathrm{Dr}$. D. Taverner, $\mathrm{Dr}$. J. P. D. Mounsey, and Dr. D. R. Smith for criticism and guidance.
The photographs were kindly provided by Miss Pegg, and secretarial assistance by Miss Rogers.

\section{REFERENCES}

Ball, K. P., Goodwin, J. F., and Harrison, C. V. (1956). Massive thrombotic occlusion of the large pulmonary arteries. Circulation, 14, 766.

Brenner, O. (1935). Pathology of the vessels of the pulmonary circulation. V. Tuberculosis of the pulmonary vessels. Arch. intern. Med., 5, 1189.

Covey, G. W. (1943). Chronic cor pulmonale with report of a case. Ann. intern. Med., 18, 851.

Dimond, E. G., and Jones, T. R. (1954). Pulmonary artery thrombosis simulating pulmonic valve stenosis with patent foramen ovale. Amer. Heart f., 47, 105.

Fowler, W. M. (1934). Obliterating thrombosis of the pulmonary arteries. Ann. intern. Med., 7, 1101.

Hanelin, J., and Eyler, W. R. (1951). Pulmonary artery thrombosis: Roentgen manifestations. Radiology, 56, 689.

Hollister, L. E., and Cull, V. L. (1956). The syndrome of chronic thrombosis of the major pulmonary arteries. Amer. F. Med., 21, 312.

Kampmeier, R. H. (1934). Thrombosis of main branches of the pulmonary artery, with a case report and review of the literature. $\mathcal{f}$. thorac. Surg., 3, 513.

Keating, D. R. (1955). Thrombosis of pulmonary arteries. Amer. F. Surg., 90, 447.

—, Burkey, J. N., Hellerstein, H. K., and Feil, H. (1953). Chronic massive thrombosis of pulmonary arteries. A report of seven cases with clinical and necropsy studies. Amer. F. Roentgenol., 69, 208.

Magidson, O., and Jacobson, G. (1955). Thrombosis of the main pulmonary arteries. Brit. Heart f., 17, 207.

Middleton, W. S. (1943). Abdominal pain in pulmonary thrombosis. Ann. intern. Med., 18, 345.

Savacool, J. W., and Charr, R. (1941). Thrombosis of the pulmonary artery. Amer. Rev. Tuberc., 44, 42.

Tench, W. R. (1955). The triad of tachycardia, digitalis toxicity and mercurial-fast edema in congestive heart failure complicated by pulmonary embolism. Amer. 7 . Med., 19, 869.

Wolff, L. (1952). Pulmonary embolism. Circulation, 6, 768. 